\title{
Construction of College English Autonomous Learning Mode Based on Task-based Learning under the Network Environment
}

\author{
Wang Guili \\ School of Foreign Languages \\ Eastern Liaoning University \\ Dandong city, China \\ ddwg12008@163.com
}

\begin{abstract}
The autonomous learning is an important and efficient approach to enhance the learners' language acquisition. In recent years, the empirical study of autonomous learning of the scholars in our country has also achieved great progress. Combined the task-based teaching theory and the students' real conditions, this study comes up with the consumption of the construction of college English autonomous learning mode based on task-based learning under the network environment with the objective to guide the students to carry out autonomous learning and practically improve the students' autonomous learning ability. Through the classroom observation, interviews, data-collection and evaluation and monitoring, it was found that this new learning mode has a significant effect on the students' language proficiency. And the exploration of this new teaching mode will not only provide the reference for the effectiveness of the autonomous learning under the network environment, but also provide the support for the reform of reducing the class hours of the college English course.
\end{abstract}

Keywords-network environment; task-based; college English; autonomous learning; learning strategies

\section{INTRODUCTION}

With the coming of knowledge economy and information age, the change of the learning mode has become an important content of the curriculum reform. With the publish of "College English Course Teaching requirement" in 2007, college English teaching reform depended on the modern information technology has become a hot issue and the cultivation of students' autonomous learning has become the focus of the college English teaching reform in recent years in Chinese colleges and universities, which also corresponds with the trend of cultivating the students' innovative ability and learning style in the international educational community. However, due to the influence of the deep-rooted traditional teaching conception and exam-oriented education, in China the traditional classroom teaching activities focus much more on the explanation and memorization of the knowledge and neglect the cultivation of the autonomous learning ability and innovative consciousness of the students. Although we set the priority of cultivating the students' autonomous learning ability during the college stage, most of the students' English autonomous learning is still in the reactive autonomy stage promoted by the teachers because of many elements, such as students' knowledge, ability, attitude, emotion motivation and quality. As a result, it is a very important issue to probe the method of promoting the autonomous learning ability of the students and construct the effective autonomous learning mode.

After many years' reform and exploration, our university college English course has developed a scientific and reasonable teaching mode and evaluation mechanism aimed at promoting the development of the students' autonomous learning ability. Depended on the advanced information technique and relied on the online teaching system of New Horizon of Foreign Language Teaching and Research Press, $3+1+X$ college English teaching mode completely changed the single classroom teaching mode and reflected the students-centered position and promoted the students' autonomy and creativity. However, as a newly-built local university, most of the students have something in common due to all kinds of reasons: such as poor English base, weak metacognition, poor management of learning task, lacking in the necessary learning style and effective learning strategies required by the autonomous learning under the network environment.

Directed at the practical problems occurred at the process of our university (Eastern Liaoning University) carrying out " $3+1+X$ " teaching mode combined with the network autonomous learning, this study comes up with the consumption of the construction of college English autonomous learning mode based on task-based autonomous learning under the network environment and combines with the task-based teaching methods to guide the students to learn autonomously and further perfect the teaching mode. This study has two purposes: on the one hand, it is to check the effectiveness of cultivating the students' autonomous learning ability of the existing teaching mode .On the other hand, we hope the exploration of this new teaching and learning mode will not only provide the reference for the effectiveness of the autonomous learning under the network environment, but also break through the frame of the traditional teaching to form a new teaching concept, and thus provide the support for the reform of reducing the class hours of the college English course. 


\section{THEORY BASE OF CARRYING OUT TASK-BASED AUTONOMOUS LEARNING MODE}

Task-based learning is the most influential language teaching mode in 1980s after many scholars and researchers' study and practice, which has a profound effect on the language teaching. "The two different theory bases of the task-based language application and learning are respectively psychological linguistics and sociocultural theory" (Gong Yafu, Luo Shaoqian) [1].Ellis (2000) thought that task-based language teaching had two theory modes, one is Long's interactive hypothesis and the other is Skehan's cognitive approach. Long and Skehan pointed out that form the perspective of psychological linguistics, the process of people mastering the language is the process of mind operation of the information processing and language application, and the task played a special role, which not only guide the students to participate in this process but also made the learners learn how to process the information during the learning process. So we can say "the interactive hypothesis and the cognitive approach regard the task from the task quality itself, while the researchers of the sociocultural theory concentrate much more on how the task is completed and how the students and teachers interacted during the process of completing the task and how it help the learners during the process of completing the task" (Ellis, 2000:210) [2]. Task-based language teaching advocates the learning process should be filled with the authentic personal meaning and requires the teachers to learn to promote the students' whole person education development, learning ability development, active emotional element and healthy personality development. The task-based teaching fully reflects the features of the social constructivist theory: such as self-discipline, self-concept, self-confidence, self-choice, sense of self-efficiency, autonomy and interaction, which plays a crucial role in cultivating the students' autonomous leaning ability and innovative ability. In a sense, the pursuit of the task-based language teaching running after is to fully explore the students' personality and potential and arouse their enthusiasm to the maximum point and thus help to them set up their confidence to increase the opportunity to learning autonomously and creatively. And it is also the theory base of the construction of college English autonomous learning mode based on task-based learning under the network environment.

The task-based autonomous learning mode based on the frame of task-based language theory and the starting point of cultivating the students' learning autonomy, combining the evaluation system and five-in-one monitoring system. This new learning mode is featured by student-centered and learners' autonomy, and place the students' need, motivation and interest in the nuclear position so as to encourage them to choose and explore autonomously and creatively. Moreover, it is beneficial to the students' personality development and lays a solid foundation for their lifelong learning and sustainable development. The implementation of this new learning mode greatly perfect the current $3+1+X$ College English teaching mode.

\section{CONSTRUCTION OF TASK-BASED AUTONOMOUS LEARNING} MODE

The nuclear concept of task-based language learning is human-oriented and student-centered. So our task-based autonomous learning mode has the following traits: cultivate the students' autonomous learning, independent thinking and problems solving abilities through the autonomous learning; focus on the students' autonomous activities and the learning process designed and controlled by the students during the task process; develop the students' awareness and ability of creatively completing the task and inquiring the task guided by the teachers; make the students obtain the abilities of developing knowledge, capacity, attitude, emotion and personality and the cooperative ability during the practice and exploration.

The effective integration of task-based autonomous learning mode under the network environment with the traditional classroom teaching mode is aimed at applying the advanced network technique to cultivate the students' autonomous learning ability. These goals include: cultivate the effective learning strategy; find the personalized learning methods suitable for yourself; set the learning plans and goals; encourage the students to adopt the practical goals and time frame and cultivate the abilities of self-evaluation and self-monitor.

According to the above goals, the project group divides the experimental process into three stages: the stage of cultivating the interest (Jan-Feb, 2014); the stage of learning strategy cultivation and adjustment (Mar-July, 2014); the stage of the integration of the traditional classroom and network classroom (Sep-Dec, 2014). The three stages of the experiment are interactive and continually recycled and the cultivation of the students' interest and learning strategy is all through the three stages.

\section{A. Interest Cultivation}

As we all know, interest is the first teacher of learning. Learning burnout is mainly resulted from lack in the learning interest and motivation. One of the key factors of success of the task-based autonomous learning mode under the network environment is to arouse the students' task motivation and cultivate the permanent learning interest through a variety of task activities. "Attract the students' attention and arouse their interest and passion of active participation is the basic English teaching requirement and the basic situation of any teaching" (Davis, P\&Pearse, E., 2000:4) [3]. With the enough learning interest and strong learning motivation, the students can only actively participate in all kinds of learning tasks. As a consequence, one of the priorities of us is how to arouse the students' learning interest in the traditional classroom. First of all, we design a questionnaire to know the purpose and motivation of learning English. According to the questionnaire, we find that most students' learning motivation belong to the instrumental motivation, whose purposes are to study abroad, pass the examination, take the postgraduate examination and so on. So in the teaching process, we start from the students' motivation and interest to satisfy the students' demands of knowledge increase and employment development. First, make students properly realize the importance of learning English; 
second, create the harmonious teachers and students' relationship; third, adopt vivid and colorful teaching methods; and create real and straight language learning environment. The stage of interest cultivation laid a strong foundation for the task-based autonomous learning under the network environment.

\section{B. Learning strategy cultivation}

The home and abroad researches show that the learning strategy guidance can greatly promote the cultivation of the autonomous learning ability. Any "successful learners are contributed to the effective learning strategy" (Wen Qiufang, 1966:22) [4].So the cultivation of the learning strategy is another key factor to the success of the task-based autonomous learning mode. According to Holec(1981), "the autonomy of the mature learners mainly are the following: set the learning goals; set the learning contents and process; choose the learning methods and skills; monitor the learning process, such as rhythm, time and place; evaluate the learning effect'[5]. So in the process of the traditional classroom teaching, we consciously give students some guidance of language learning strategies, such as cognitive strategies, metacognitive strategies, communication strategies, social strategies and affective strategies. Among those strategies, we laid more emphasis on the cultivation of the metacognitive strategies because metacognitive knowledge includes all facts learners acquire about their own cognitive process as they are applied and used to gain knowledge and acquire skills in various situations. In a sense, metacognitive strategies are skills used for planning, monitoring and evaluating the learning activity. We have introduced the basic language strategies to the students for the sake of helping them find the learning strategies and methods that suit them best and encourage them to apply these strategies to the network autonomous learning. In summary, during the process of the task-based autonomous learning mode, helping the students effectively apply the learning strategy will not only improve the learning efficiency but also help them form the autonomous learning ability and lay a strong foundation for all lifelong study.

\section{Integration of Traditional Classroom with Network Classroom}

The traditional classroom teaching is only an important link of the foreign language teaching and practice, so we set the classroom teaching goals as: solve the difficult and key points in the language learning; cultivate the students' interest and motivation; provide the suitable language input to train the basic language skills; cultivate the students' learning strategies and provide the students with the necessary guidance of network autonomous learning. While in the process of task-based autonomous learning under the network environment, teachers choose and arrange the learning materials based on the learners' elements including self-confidence, motivation, the prior learning experience, learning attitude, language skills, cultural knowledge awareness and language knowledge and task elements including relativity, complexity, context information value provided before the task, understandable levels of task language, learning help obtained, grammar correctness and time allowed. The design of practice and activities are reflected by the form of the task, while the task is meant to arouse the students' interest and guide them obtain and explore knowledge spontaneously, and thus enable them not only master the knowledge but also develop the autonomous learning ability. The practice shows that the integration of the task-based autonomous learning with the traditional classroom can better complete the teaching task and goals of the network teaching and realizes the task-based teaching mode featured by student-centered and teacher-oriented and promote the students' comprehensive and personalized development.

\section{Evaluation}

Evaluation is the important basis to measure the realization of the course goal, which is "not only the important basis for the teachers to obtain the teaching information and feedback, improve the teaching management and promote the learning efficiency" (Jiang Shengli, 2004) [6]. After many years' practice and summary, we built step by step the evaluation system combining formative evaluation with summative evaluation to evaluate the students from multi-level, such as learning attitude, the process of completing the learning task, learning methods and strategy and autonomous learning situation. The task-based autonomous learning mode under the network environment is a kind of opening learning activities, so the multi-evaluation refers to various flexible evaluating methods to give full play their advantages, that is, its functions of guidance, stimulation and development and let the students be fully aware of their own advantages and disadvantages and timely revise their learning plans and strategies.

However, periodical evaluation alone is not enough to provide sound assessment. As metacognitive development is a kind of mental process, relevant techniques are needed for monitoring the learning process.

\section{E. Monitoring}

The practice shows that the nuclear learning concept under the network environment is student-centered and learner's autonomy, which depends on the support of network technique to advocate the autonomous learning mode featured by opening, interactive and cooperative. As a result, the students' self-monitoring is very important to the success of the autonomous learning.

According to the practical conditions of our university, we construct a five-in-one multi-monitoring system participated by the students, teachers, teaching management department, network technique monitoring and measurement and evaluation monitoring. The construction of the monitoring system, on the one hand, ensures the output of the autonomous learning efficiency; on the other hand, promotes the sustainable development of network autonomous learning mode.

In addition, the monitoring of network autonomous learning is not to impose the monitor and intercept unit to the students but to provide the students with the appropriate data and information through the metacognition monitoring theory, autonomous learning theory and the relative intellectual technique of self-monitoring under the network environment for the learners to help them improve their metacognition monitoring ability. 


\section{EFFECT OF TASK-BASED AUTONOMOUS LEARNING MODE}

After a year's teaching practice, the task-based autonomous learning mode is recognized and accepted by most of the students and achieve some effects: First, learning interest is increased and learning motivation is changed: After the implementation of the integration of the task-based learning mode and $3+1+X$ teaching mode, the students' interest of learning English is improved greatly and $93 \%$ of the students prefer this kind of learning mode which they can choose the learning materials interest them and learning methods. Moreover, $45 \%$ of the students' learning motivation has changed from the instrumental motivation lacking in learning interest to the integrative motivation beneficial to the language learning. Second, the self-confidence and autonomous learning ability are greatly improved. During the task-based autonomous learning mode, the students can choose the personalized learning methods and learning strategies which fit for their own conditions best according to their own interest and conditions. They won't be afraid of making mistakes under the network environment and can clearly realize their gradual progress and in return which greatly strengthen their learning autonomy. Third, the comprehensive application ability of language is improved obviously. After a year's teaching practice, the students' abilities of listening, speaking, reading, writing and translation have been improved greatly, especially the listening and speaking ability, compared to the pre-experiment, the experimental class' listening and speaking achievement are increased by $45 \%$ and $37 \%$ respectively and the passing rate of college English Test Band 4 for the first time reached $78 \%$ in 2013.

\section{CONCLUSION}

The task-based autonomous learning mode is a new teaching mode of the integration of our university's " $3+1+X$ "teaching mode. After a year's teaching practice, the current conditions is stable and achieve the satisfactory effects: most students' autonomous learning ability and self-monitor ability has been improved greatly; they can set up the learning plan ,the learning goal, learning strategy depending on their own conditions and own the basic ability and traits of the autonomous learners. However, during the practice, we also find some problems worth our attention: first, the students' individual difference and regional difference. There exists great regional difference in our country, so the accesses to the language conditions, the students' mind and life style also have great difference. Some students from the remote rural areas are ignorant completely to the computer and internet technique. The language levels of the entrance examination to the colleges of the students are also different. All of these bring great challenge to the task-based autonomous learning mode. As a result, first of all, we should strengthen the students' computer technique training. Second, we should give the students basic language learning strategies guidance to satisfy the requirements of the autonomous learning under the network environment. Last but not the least, we should focus much more on the teachers' teaching autonomy: 'teachers' autonomy and students' autonomy is just like the two sides of a coin, while the former is the premise and guarantee of the latter (Shu Dingfang, 2004) [7]. However, although most teachers realize the importance of the autonomous learning for the students, they have little to do on the language learning strategies to the students due to lacking in the formal strategy education when they are studying in university. As a result, the teachers' strategy guidance should be covered as a necessary part in the teacher training. As long as the teachers own the real teaching autonomy, the students' learning autonomy can be achieved to the large extent.

To sum up, the bask-based autonomous learning mode can be effective in promoting the students' language acquisition, but it all relies on how it is operated. Taking the characteristics of the autonomous learning into account, cooperative group learning may be covered in the further strategy guidance.

\section{REFERENCES}

[1] GongYafu, Luo Shaoqian ,"Task-Based Language Teaching," Second ed.Beijing:Beijing Educational Press, July 2007.

[2] W.Ellis s,R,"Tasked-based languagelLearning and teaching," [J].Language Teaching Research, 2000,4,pp.210

[3] Wen Qiufang, "On English Learning Stratey," Shanghai:Shanghai Foreign Language Educatoinal Press, 1996, pp.22.

[4] Davis, P. \& Pearse, E, "Success in English Teaching," Oxford, Oxford University Press, 2000:4.

[5] Holec, H, "Autonomy and Foreign Language Learning ," Oxford, Pergamon Press, 1981

[6] Jiang Shengli, "Monitoring of network autonomous learning", [J] Modern Education Techniques, 2004, (5) pp.46-48

[7] Shu Dingfang, "Foreign Language Teaching and Reform: problems Countermeasures," Shanghai Foreign Language Educational Press, Shanghai, 2004, pp.258. 